\title{
Correction: Conceptualizing mental disorders as deviations from normative functioning
}

\author{
Andre F. Marquand ${ }^{1,2,3} \cdot$ Seyed Mostafa Kia $\mathbb{D}^{1,2} \cdot$ Mariam Zabihi, $^{1,2}$ Thomas Wolfers ${ }^{1,2} \cdot$ Jan K. Buitelaar $\mathbb{D}^{1,2,4} \cdot$ \\ Christian F. Beckmann ${ }^{1,2,5}$
}

Published online: 26 June 2019

(c) The Author(s) 2019. This article is published with open access

\section{Correction to: Molecular Psychiatry \\ https://doi.org/10.1038/s41380-019-0441-1; \\ published online 14 June 2019}

In the original version of this article, panel labels in the legend of figure 1 were incorrectly positioned alongside non-corresponding panel descriptions. The legend of figure 1 has now been updated. This has been corrected in both the PDF and HTML versions of the article.

Andre F. Marquand

a.marquand@donders.ru.nl

1 Donders Centre for Cognitive Neuroimaging, Donders Institute for Brain, Cognition and Behaviour, Radboud University,

Nijmegen, the Netherlands

2 Department of Cognitive Neuroscience, Radboud University Medical Centre, Nijmegen, the Netherlands

3 Department of Neuroimaging, Centre for Neuroimaging Sciences, Institute of Psychiatry, King's College London, London, UK

4 Karakter Child and Adolescent Psychiatric University Centre, Nijmegen, the Netherlands

5 Oxford Centre for Functional Magnetic Resonance Imaging of the Brain (FMRIB), University of Oxford, Oxford, UK
Open Access This article is licensed under a Creative Commons Attribution 4.0 International License, which permits use, sharing, adaptation, distribution and reproduction in any medium or format, as long as you give appropriate credit to the original author(s) and the source, provide a link to the Creative Commons license, and indicate if changes were made. The images or other third party material in this article are included in the article's Creative Commons license, unless indicated otherwise in a credit line to the material. If material is not included in the article's Creative Commons license and your intended use is not permitted by statutory regulation or exceeds the permitted use, you will need to obtain permission directly from the copyright holder. To view a copy of this license, visit http://creativecommons. org/licenses/by/4.0/. 